\title{
Effects of Nutrients on Self-Inhibition of Germination of Conidia of Glomerella cingulata
}

\author{
BY B. T. LINGAPPA AND YAMUNA LINGAPPA \\ College of the Holy Cross, Worcester, Massachusetts, U.S.A.
}

(Received 22 March 1965)

\begin{abstract}
SUMMARY
The percentage germination of suspensions of washed conidia of Glomerella cingulata decreased with increasing concentrations of the conidia in distilled water. With 30 conidia $/ \mathrm{mm}^{2}$ greater than $90 \%$ germination was obtained, whereas the conidia from the same batch gave less than $3 \%$ germination when there were 3000 conidia $/ \mathrm{mm} .{ }^{2}$. This inhibition of germination of crowded conidia was nullified by adequate amounts of peptone; but aeration by shaking had no influence, so that oxygen lack was ruled out as a factor in the inhibition. Various adsorbents, ion exchange resins, vitamins and germination stimulating chemicals were ineffective in inducing germination of crowded conidia. Czapek-Dox mineral solution, Hoagland's mineral solution and Czapek-Dox glucose solution gave respectively 10,30 and $40 \%$ germination of crowded conidia. The germination of conidia was improved by repeated washing with distilled water. Addition of various mineral salts and trace elements ( $\mathrm{Mg}, \mathrm{Fe}, \mathrm{Mn}, \mathrm{Bo}, \mathrm{Zn}, \mathrm{Mo}, \mathrm{Cu}$ ) were relatively ineffective or toxic. Glucose, or mannitol did not induce germination. Peptone and phenylalanine were most effective in promoting the germination of crowded conidia, but only in massive doses. Bimodal response of germination of conidia to added nutrients was noticed. Since the conidia germinated, when present at low concentrations in redistilled water without added nutrients, the conidia could not be considered as nutritionally deficient. The beneficial effect of nutrients in promoting the germination of crowded conidia may be due to inactivation of inhibitory metabolites from the conidia.
\end{abstract}

\section{INTRODUCTION}

Conidia of Glomerella cingulata (Stoneman) Spaulding and Schrenk have been used extensively for bioassay and fungicide studies. The results of germination of conidia of this fungus reported from time to time have shown many inconsistencies. Hawkins (1913) found no difficulty in germinating the conidia in distilled water, whereas Goldsworthy \& Green (1938) found that the leached conidia required an exogenous supply of 'accessory' substances for germination. Germination of cleaned conidia of $G$. cingulata was obtained by Lin (1945) only after addition of suitable sources of carbon, nitrogen, phosphorous, magnesium and sulphur Richardson \& Thorn (1962) and Lingappa \& Lingappa (1964) reported that washed conidia of $\boldsymbol{G}$. cingulata germinated in distilled water without the addition of nutrients, and that the germination of conidia was inversely proportional to the concentration of conidia. This inhibitory effect of concentration of conidia on germination may be called self-inhibition of germination. Washed conidia of $G$. cingulata germinated readily in distilled water when their number was less than $100 / \mathrm{mm} .{ }^{2}$. On the other hand, we had repeatedly observed that the germination of conidia was inhibited 
when dispersed in concentrations above $3000 / \mathrm{mm} .^{2}$ in highly nutritive laboratory media such as full strength potato glucose agar. Experiments devised to examine these inconsistencies in the germination behaviour of conidia of G. cingulata are reported in this paper.

\section{METHODS}

A culture of Glomerella cingulata was derived from Dr C. Leben's isolate no. 22 which Dr Leben had found in $\mathbf{1 9 5 4}$ to be pathogenic to Jonathan apples. It was originally isolated from apples by $\mathrm{Dr} \mathrm{J}$. O. Andes as isolate G. (personal communication from Dr C. Leben, Ohio Agriculture Experiment Station, Wooster, Ohio). A single-spore isolate from this culture which sporulated better in our laboratory conditions was selected and designated G. 21. Potato glucose agar (PDA; Johnson, Curl, Bond \& Fribourg, 1960) or potato sucrose agar which contained $8.5 \%(\mathrm{w} / \mathrm{v})$ sucrose in place of $2 \%(\mathrm{w} / \mathrm{v})$ glucose in PDA or the respective liquid media without agar, were used to grow this fungus. Liquid cultures were shaken on a rotary shaker at $150 \mathrm{rev} / \mathrm{min}$. at $\mathbf{2 5}^{\circ}$ in a temperature-controlled. chamber Both liquid and solid cultures yielded abundant conidia.

Germination studies were done under aseptic conditions to avoid contamination. Conidia were dislodged into water from slopes of culture by using an inoculation needle, and quickly washed twice in redistilled water by centrifugation. Cleaned conidia were resuspended in water to read 1 unit at $400 \mathrm{~m} \mu$. in a spectrophotometer (Bausch \& Lomb, Spectronic 20). This stock suspension was serially diluted 1:1 through 10 steps. The stock and the first two dilutions were discarded and $1.5 \mathrm{ml}$. of the dilutions 3 to 10 were pipetted into separate disposable $35 \times 10 \mathrm{~mm}$. Petri dishes (Falcone Plastics, Los Angeles, California) in duplicate. The contents of the Petri dishes were finally made up to $2 \mathrm{ml}$. by adding supplements and/or water. Conidia so dispersed settled rapidly to the bottom of the Petri dish as a single layer covered by a $2 \mathrm{~mm}$. layer of water. These were incubated at $25^{\circ}$ for $8 \mathrm{hr}$. The conidia were killed and stained by adding $0.1 \mathrm{ml}$. rose bengal/dish. The staining solution was prepared by dissolving $1 \mathrm{~g}$. rose bengal in $100 \mathrm{ml}$. of $5 \%$ (w/v) aqueous solution of phenol containing $0.01 \mathrm{~g} . \mathrm{CaCl}_{2}$ (Waksman, 1932). This solution was filtered and diluted $1 / 3$ with aqueous phenol. From each treatment the germinated conidia in eight separate fields or of 500 or more conidia were counted randomly. All conidia in the microscope fields $\left(0 \cdot 102 \mathrm{~mm} .^{2}\right.$ area) were counted, and the number of conidia/mm..$^{2}$ versus $\%$ germination calculated. The dosage (amount of nutrients or number of conidia) was plotted on log scale and the response ( $\%$ germination) on probit scale. In this work conidia were considered to be germinated when they produced discernible germ tubes longer than the minor diameter of the conidium.

For nutritional work bacteriological grade substances, Bacto-Peptone (Difco Laboratories, Detroit, Michigan) and reagent grade chemicals were used. Redistilled water from a Pyrex glass still was used throughout.

Czapek-Dox mineral solution contained (g.): $\mathrm{NaNO}_{3}, \mathbf{3} ; \mathrm{K}_{2} \mathrm{HPO}_{4}, \mathbf{1} ; \mathrm{MgSO}_{4} .7 \mathrm{H}_{2} \mathrm{O}$, $0.5 ; \mathrm{KCl}, 0.5 ; \mathrm{FeSO}_{4} .7 \mathrm{H}_{2} \mathrm{O}, 0.01$; in 1 1. distilled water; (Johnson et al. 1960).

Modified Hoagland's solution contained (g.): $\mathrm{Ca}\left(\mathrm{NO}_{3}\right)_{2} \cdot 4 \mathrm{H}_{2} \mathrm{O}, 1 \cdot 18 ; \mathrm{MgSO}_{4} \cdot 7 \mathrm{H}_{2} \mathrm{O}$, $0.493 ; \mathrm{KNO}_{3}, 0.506 ; \mathrm{KH}_{2} \mathrm{PO}_{4}, 0.136 ;$ ferric tartrate, $0.01 ; \mathrm{H}_{3} \mathrm{BO}_{3}, 0.00286$; $\mathrm{MnCl}_{2} .4 \mathrm{H}_{2} \mathrm{O}, 0.00362 ; \mathrm{ZnSO}_{4} .7 \mathrm{H}_{2} \mathrm{O}, 0.00022 ; \mathrm{MoO}_{3}, 0.00014 ; \mathrm{CuSO}_{4} .5 \mathrm{H}_{2} \mathrm{O}$, 0.00008 ; in 1 l. distilled water (Thimann \& Edmondson, 1949). 


\section{RESULTS}

Eight dilutions of washed conidia were uniformly distributed in duplicate Petri dishes to give average conidial concentrations from 30 to 3000 conidia/mm. ${ }^{2}$ in distilled water. The data obtained from these experiments clearly indicated that the washed conidia gave $90 \%$ or better germination when present at concentrations of $30 / \mathrm{mm}^{2}$, whereas the conidia from the same lot gave less than $3 \%$ germination when the concentration was $\mathbf{3 0 0 0}$ conidia $/ \mathrm{mm}^{2}$ in water (Fig. 1). Different batches of conidia from cultures grown under different conditions gave $80 \%$ or less germination in water. Examination of water controls in Fig. 2, 3 and 5 showed, however, that $50 \%$ conidia germinated in water at concentrations of about $100 / \mathrm{mm} .^{2}$ The germination of conidia was directly proportional to the concentration of conidia in water (Fig. 1): an instance of 'self-inhibition'.
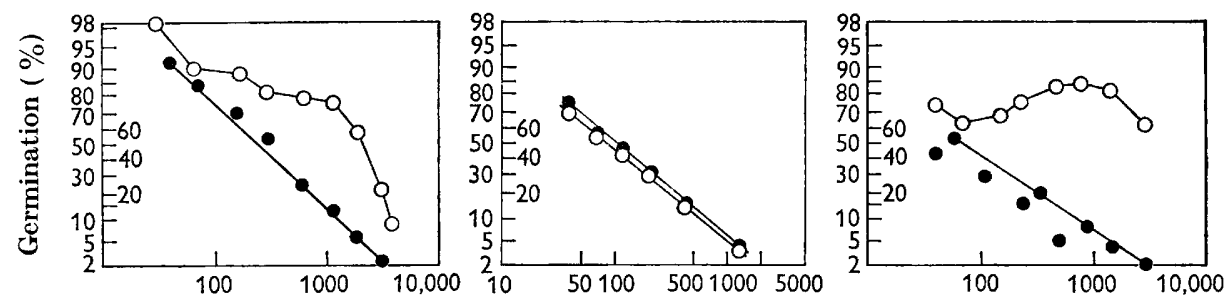

Fig. 1

Concentration of conidia (no./mm. ${ }^{2}$ )

Fig. 2

Fig. 3

Fig. 1. Germination of conidia (probit scale) of Glomerella cingulata, in different densities (log scale), in $1.25 \mathrm{mg} . / \mathrm{ml}$. peptone solution (O-O) and in water (O-O).

Fig. 2. Germination of conidia (probit scale) of Glomerella cingulata, in different densities (log scale), in $30 \mathrm{mg} . / \mathrm{ml}$. sucrose solution (O-O) and in water (O-O).

Fig. 3. Germination of conidia (probit scale) of Glomerella cingulata, in different densities (log scale) in $12.5 \mathrm{mg} . / \mathrm{ml}$. L-phenylalanine $(\mathrm{O}-\mathrm{O})$ and in water (O-O).

The dependence of germination on the concentration of conidia might be due to decreased availability of oxygen or of nutrients to individual conidia, or to decreased ability of the conidia to utilize these in presence of toxic metabolites in or from the conidia. Decreased availability of oxygen did not appear to be responsible for this effect. Suspensions of conidia of different concentrations were shaken, with or without peptone, on a rotary shaker at 50,100 and $200 \mathrm{rev} . / \mathrm{min}$. They did not show increased germination over the static controls. Germination was increased markedly by adding peptone (Fig. 4).

\section{Influence of various nutrients}

More conidia germinated in potato extracts or in peptone solutions than in water. Therefore components of various laboratory media were separately added to suspensions of crowded conidia. About 3000 conidia $/ \mathrm{mm} .^{2}$ were enough to give negligible germination in water and complete germination in peptone solution (30 mg./ml.), but were not too concentrated to count. This concentration was obtained by serial dilution no. 3 and will be referred to as crowded conidia. Addition of D-glucose, sucrose or D-mannitol $30 \mathrm{mg}$. $/ \mathrm{ml}$. showed no significant effect on 
germination (Fig. 2, 5). Figure 1 shows that high \% germination was readily obtained without addition of nutrients when the conidia were less crowded. On the other hand \% germination of crowded conidia was directly proportional to the amount of peptone added (Fig. 4), and that even in presence of peptone increasing the concentration of conidia resulted in progressively less germination (Fig. 1). The amount of peptone required to annul inhibition by crowding and to promote

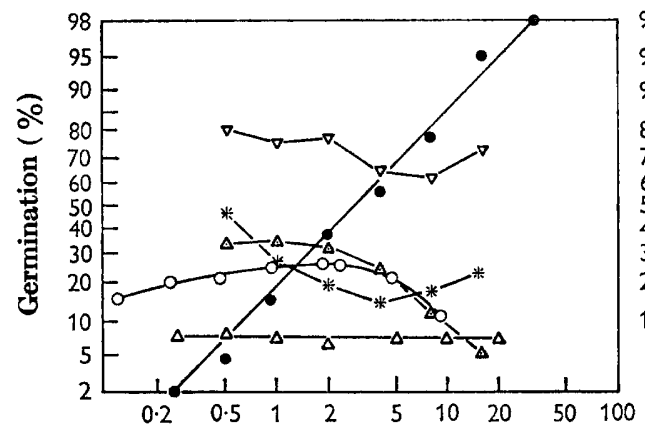

Concentration of nutrients (mg./ml.)

Fig. 4

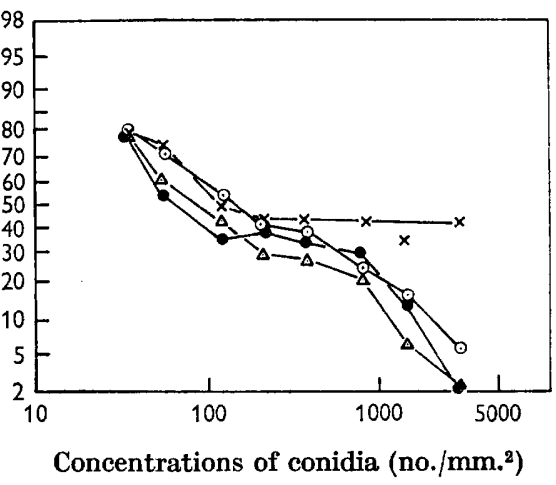

Fig. 5

Fig. 4. Germination of conidia (probit scale) of Glomerella cingulata, in increasing amounts (log scale), of peptone $\left(\mathrm{O}_{-}\right)$, L-phenylalanine $(\nabla-\nabla), \mathrm{L}$-asparagine $(\triangle-\Delta)$ DL-alanine $(*-*)$, Hoagland's salts $(O-O)$, and Czapek-Dox salts $(\triangle-\triangle)$; conidia were $3000 / \mathrm{mm}^{2}$.

Fig. 5. Germination of conidia (probit scale) of Glomerella cingulata, in different concentrations (log scale), in Czapek-Dox solution $(\odot-\odot)$, in $30 \mathrm{mg} \cdot / \mathrm{ml}$. glucose solution $(--)$, in Czapek-Dox with $30 \mathrm{mg} . / \mathrm{ml}$. glucose $(x-x)$ and in water $(\triangle-\triangle)$.

Table 1. Effect of concentration of peptone on crowded conidia $\left(3000 / \mathrm{mm}^{2}{ }^{2}\right)$ of Glomerella cingulata

\begin{tabular}{|c|c|}
\hline $\begin{array}{l}\mu \mathrm{g} \text {. peptone } / \mu \mathrm{g} \text {. } \\
\text { conidia } \\
\text { (oven dry wt.) }\end{array}$ & $\begin{array}{c}\text { Germination } \\
(\%)\end{array}$ \\
\hline 0.428 & 0.9 \\
\hline 0.855 & $4 \cdot 0$ \\
\hline 1.710 & $15 \cdot 3$ \\
\hline $3 \cdot 422$ & $31 \cdot 8$ \\
\hline $6 \cdot 844$ & 56.5 \\
\hline $13 \cdot 687$ & $77 \cdot 5$ \\
\hline $27 \cdot 374$ & 94.7 \\
\hline $54 \cdot 747$ & $99 \cdot 0$ \\
\hline
\end{tabular}

the emergence of germ tubes was nearly 30 to 50 times the weight of the conidia (Table 1). These results suggested that only a very minor component of peptone was involved in annulling the inhibition or that some component of the peptone might be serving a non-nutritional role such as binding toxic metabolites of the conidia.

Casein hydrolysate (vitamin free) was ineffective from 1 to $20 \mathrm{mg} . / \mathrm{ml}$. Richardson \& Thorn (1962) found, of 19 amino acids tested that only arginine, asparagine, aspartic acid, glutamic acid, glutathione, leucine, phenylalanine, tryptophan and tyrosine were effective in bringing about germination of crowded conidia. The 
concentration of conidia, duration and manner of incubation and criterion of beneficial effect on germination used by these workers were different. Therefore we tested those amino acids and found that L-glutamic acid and glutathione gave a maximum of $10 \%$ germination between 0.01 and $1 \mathrm{mg} . / \mathrm{ml}$., and less germination at higher concentrations $(1.6 \mathrm{mg} . / \mathrm{ml}$.). L-asparagine gave $20-35 \%$ germination in concentrations from 0.1 to $1.6 \mathrm{mg}$. $/ \mathrm{ml}$. The effect of asparagine above $0.5 \mathrm{mg} . / \mathrm{ml}$. is shown in Fig. 4; higher concentrations were toxic. L-phenylalanine and DL-alanine showed a bimodal response, inducing high germination at $0.5 \mathrm{mg} . / \mathrm{ml}$. and again at $16 \mathrm{mg} . / \mathrm{ml}$. (Fig. 4). Phenylalanine was like peptone in its effect on increasing concentrations of conidia (Fig. 3). Although phenylalanine induced germination, like peptone, the germ tubes formed ended in appressoria and did not grow any further. In peptone the germ tubes were robust, branched and grew profusely.

Table 2. Effect of various substances on germination of crowded conidia (3000/mm..$\left.^{2}\right)$ of Glomerella cingulata

\section{Substances}

Silica gel (E. Merck A.G. Darmstadt, Germany)

Cellulose powder (Macherey, Nagel \& Co. Düren, Germany)

Aluminum oxide (Merck)

Cation exchange resin (Rexyn 101 (Na), (Fisher Scientific Co., New York, N.Y.)

Anion exchange resin (Rexyn CG (Cl), (Fisher Scientific Co.)

Charcoal, Bacteriological (Oxo Ltd., London)

Thiourea (Baker \& Adams, Allied Chemicals, New York, N.Y.)

Adenosine (Nutritional Biochemicals Corp. Cleveland, Ohio)

L-cysteine $\mathrm{HCl}$ (Nut. Biochem Corp.)

L-cystine (Nut. Biochem. Corp.)

Menadione (K \& K Labs. Plainview, N.Y.)

Coumarin (Aldrich Chem. Co., Milwaukee, Wisc.)

$\dagger$ Biotin (Nut. Biochem. Corp.)

$\uparrow$ Thiamine HCl (Eastman)

$\dagger$ Riboflavin (Merck)

Water control

$3 \%(w / v)$ Peptone (Difco)

\begin{tabular}{|c|c|}
\hline $\begin{array}{l}24 \mathrm{hr} \text { of } \\
\text { incubation, } \\
\text { germination } \\
(\%)\end{array}$ & $\begin{array}{l}\text { 2nd incubation } \\
8 \mathrm{hr} \text { with } \\
\text { peptone*, } \\
\text { germination }\end{array}$ \\
\hline 0 & + \\
\hline 0 & + \\
\hline 0 & + \\
\hline 0 & + \\
\hline 0 & + \\
\hline 1 & + \\
\hline 1 & + \\
\hline 5 & + \\
\hline 0 & 0 \\
\hline 2 & + \\
\hline O & 0 \\
\hline 2 & + \\
\hline$\overline{2}$ & $\ldots$ \\
\hline 2 & $\ldots$ \\
\hline 2 & $\ldots$ \\
\hline 1 & + \\
\hline 98 & $\ldots$ \\
\hline
\end{tabular}

* Nearly all spores germinated $=+$, no spores germinated $=0$, results not available $=\ldots$..

$\dagger$ Germination was similar in all concentrations, viz. $0.005,0.05,0.2 \mu \mathrm{g} . / \mathrm{ml}$.

Other agents tested included various adsorbents, vitamins and chemicals used by various investigators for the activation of dormant biological forms. Adsorbents were added $1 \mathrm{mg} . / \mathrm{ml}$. to conidial suspension and other substances were in $10^{-4} \mathrm{M}$ final concentration unless otherwise mentioned. These preparations were incubated for $24 \mathrm{hr}$, instead of the usual $8 \mathrm{hr}$, and the conidia counted without killing and staining. Peptone was then added to the Petri dishes and incubation continued for $8 \mathrm{hr}$. The data shown in Table 2 indicated that the adsorbents, various activating chemicals, and vitamins tested were non-toxic but ineffective in inducing the germination of crowded conidia. Re-incubation with peptone indicated that menadione and 2,4-dinitrophenol were toxic at the concentrations used. 


\section{Effect of mineral salts}

Conidia were dislodged from slopes of culture as before and the suspensions quickly centrifuged. The deposited conidia were resuspended in sterile distilled water and a sample suitably diluted and put for germination. The remaining spores were repeatedly washed with glass redistilled water, taking samples for germination after 5, 10 and 20 washings. The results shown in Table 3 indicate great improvement in the germination of conidia when washed 5 times or more, as compared with unwashed conidia. When Czapek-Dox mineral solution was used for washing, primarily to prevent osmotic damage to spores, a high \% germination was obtained without any addition of carbon source. Corresponding series in peptone $5 \mathrm{mg} . / \mathrm{ml}$. solutions gave uniformly $90 \%$ or higher germination at all spore densities, irrespective of the medium or number of washings.

Table 3. Effect of washing on germination of crowded conidia $\left(3000 / \mathrm{mm} .{ }^{2}\right)$ of Glomerella cingulata in water

\begin{tabular}{|c|c|c|c|c|c|c|c|c|c|}
\hline \multicolumn{2}{|c|}{ Unwashed } & \multicolumn{2}{|c|}{ Washed $5 \times$} & \multicolumn{2}{|c|}{ Washed $10 \times$} & \multicolumn{2}{|c|}{ Washed $20 \times$} & \multicolumn{2}{|c|}{$\begin{array}{c}\text { Washed } 10 \times \text { in } \\
\text { Czapek-Dox } \\
\text { solution }\end{array}$} \\
\hline $\begin{array}{c}\text { Conidia/ } \\
\text { mm. }^{2}\end{array}$ & $\begin{array}{l}\text { Germ. } \\
(\%)\end{array}$ & $\begin{array}{c}\text { Conidia/ } \\
\text { mm. }\end{array}$ & $\begin{array}{l}\text { Germ. } \\
(\%)\end{array}$ & $\begin{array}{c}\text { Conidia/ } \\
\text { mm. }\end{array}$ & $\begin{array}{c}\text { Germ. } \\
(\%)\end{array}$ & $\begin{array}{c}\text { Conidia/ } \\
\text { mm. }^{2}\end{array}$ & $\begin{array}{l}\text { Germ. } \\
(\%)\end{array}$ & $\begin{array}{c}\text { Conidia/ } \\
\text { mm. }\end{array}$ & $\begin{array}{c}\text { Germ. } \\
(\%)\end{array}$ \\
\hline 1800 & $\mathbf{5}$ & 1750 & 43 & 1300 & 37 & 1176 & 53 & 1400 & 92 \\
\hline 80 & 56 & 138 & 80 & 140 & 90 & 223 & 91 & 157 & 84 \\
\hline 22 & $\mathbf{3 3}$ & 88 & 91 & 29 & 82 & 38 & 81 & 48 & 90 \\
\hline
\end{tabular}

These experiments indicated that either a soluble inhibitor was leached away by repeated washing of the conidia or that these were accumulating stimulatory 'trace' minerals from the 'distilled' water. The later suggestion appeared possible because washing with Czapek-Dox (C-D) mineral solution gave a high stimulation of germination. This was examined by adding $\mathrm{C}-\mathrm{D}$ mineral solution into crowded conidial suspensions. The results showed (Fig. 4) that the amount of C-D salts added did not make much difference, about $10 \%$ of crowded conidia germinated throughout the range of $\mathbf{0 . 2 5} \mathrm{mg}$. to $20.04 \mathrm{mg}$. salts $/ \mathrm{ml}$. water (normal strength was $5.01 \mathrm{mg}$. salts $/ \mathrm{ml}$. water). It was also evident that the pattern of germination at different concentrations of conidia were unaffected by the addition of $\mathbf{C}-\mathbf{D}$ minerals (Fig. 5). The addition of C-D mineral salts did not show an effect on lower concentrations of conidia. Singly or in admixture these minerals, with or without glucose, were ineffective in inducing germination of conidia (Lin, 1945). But nearly $50 \%$ conidia germinated in concentration from 1000 to 3000 conidia $/ \mathrm{mm} .^{2}$ when glucose C-D salts were added (Fig. 5). To examine whether other minerals might increase germination, Hoagland's mineral solution as modified by Thimann \& Edmondson (1949) was used; it contained iron, manganese, boron, zinc, molybdenum and copper in traces. This Hoagland solution gave consistently higher germination than the corresponding C-D solution (Fig. 4). At concentrations of 1000-3000 conidia/mm. ${ }^{2} 15-20 \%$ conidia germinated in diluted Hoagland's solution $(0 \cdot 6 \mathrm{mg}$. salt $/ \mathrm{ml}$.). Normal strength Hoagland's solution $(2 \cdot 332 \mathrm{mg} . / \mathrm{ml}$.) promoted about $\mathbf{2 5} \%$ germination of crowded conidia (Fig. 4); higher concentrations were toxic. 
Trace element components of Hoagland solution were separately added in various concentrations to crowded conidial suspensions. But they did not show any stimulation of germination; concentrations greater than $\left(\mu \mathrm{g} . / \mathrm{ml}\right.$.) 0.004, $\mathrm{CuSO}_{4}$. $5 \mathrm{H}_{2} \mathrm{O} ; 0.07, \mathrm{MoO}_{3} ; 0.011, \mathrm{ZnSO}_{4} .7 \mathrm{H}_{2} \mathrm{O} ; 1 \cdot 43, \mathrm{H}_{3} \mathrm{Bo} ; 1.81, \mathrm{MnCl}_{4} .4 \mathrm{H}_{2} \mathrm{O} ; 9 \cdot 84$, $\mathrm{MgSO}_{4} \cdot 7 \mathrm{H}_{2} \mathrm{O}$ were toxic. Only $\mathrm{Mo}$ and $\mathrm{Mn}$ slightly stimulated germination (10\%) at concentrations $1 / 10$ of the preceding sentence. Ferric tartrate gave increasing germination ( $18 \%$ ) up to $8 \mu \mathrm{g} . / \mathrm{ml}$; the corresponding germination in distilled water (control) was $1 \%$.

\section{DISCUSSION}

Decreased germination due to crowding of spores had been called self-inhibition or auto-inhibition; this phenomenon is known for many fungi (Cochrane, 1958). Various studies have shown that germination of uredospores of rust fungi is prevented by the concentration of uredospores and this has been ascribed to substances which diffuse from the spores (Allen, 1957). Trimethylethylene (Forsyth, 1955), phenolic compounds, coumarins and glycosides (van Sumere, van Sumere-De Preter, Vining \& Ledingham, 1957), and glutamic and aspartic acids (Wilson, 1958) from the uredospores have been considered as possible self-inhibitors. The results of Bell (1960) suggested the existence of unidentified inhibitory substances other than glutamic and aspartic acids in the uredospores.

Conidia of Glomerella cingulata also exhibit strong self-inhibition of germination in water (Fig. 1). Washed conidia were capable of germination in increasing numbers with decreasing concentration in redistilled water; when conidia were less than $100 / \mathrm{mm}^{2}$ a large percentage of them germinated readily in water (Fig. 1). Therefore it is most likely that self-inhibition of germination of conidia might not be due to lack of nutrients. Increased concentration of conidia in water might lead to decreased supply of oxygen and of trace elements that may still be contaminating the twice distilled water, or might lead to increased concentration of self-inhibitory emanations from conidia. Improved germination of repeatedly washed conidia might be due to leaching of toxic metabolites of conidia or to accumulation of trace elements by the conidia from successive batches of water.

In as much as oxygen was ruled out as a factor in limiting germination of crowded conidia there were two questions to be investigated, viz. whether the spores depended upon an exogenous supply of some nutrients or whether self-inhibitory metabolites were responsible for the inhibitory effect of crowding. Inhibitory effect of crowded conidia was not overcome by addition of various growth stimulating and dormancy-breaking chemicals (Table 2). They included menadione, coumarin and 2,4-dinitrophenol which remove self-inhibition of uredospores (cf. Farkas \& Ledingham, 1959). These results might indicate that the mechanisms involved in the self-inhibition of germination of conidia of Glomerella cingulata might be different from those of the uredospores.

Inhibition of germination of crowded conidia $\left(3000 / \mathrm{mm} .{ }^{2}\right)$ was effectively nullified by peptone (Fig. 4). Peptone required was as much as 30 to 50 times the weight of conidia to bring about germination (Table 1). The ascospores of Neurospora tetrasperma utilize only endogenous reserves during germination (Lingappa \& Sussman, 1959) and the amount utilized was less than $10 \%$ of the spore weight and this gives an idea as to the amounts of substrates that may be required for germination of 
spores. It is inconceivable that peptone might be required in such large quantities as a nutrient source to effect germination of conidia. Therefore, it appeared to us that peptone might be antagonizing or inactivating some toxic spore metabolites. The beneficial effects of phenylalanine decreased and again increased with increasing concentration (Fig. 4) and its effect on different densities of conidia was like peptone (Fig. 3). Nearly $80 \%$ of crowded conidia germinated in both peptone and in phenylalanine solutions of $1.25 \%$ concentrations. In phenylalanine the germ tubes failed to grow and ended in appressoria. Germination was good in alanine $\mathbf{( 4 5} \%$ at $0.5 \mathrm{mg} . / \mathrm{ml}$.) and growth of germ tubes was normal but the germination of conidia decreased to $14 \%$ with $4 \mathrm{mg}$. alanine $/ \mathrm{ml}$. These effects of amino acids indicate that the beneficial effects of peptone might be most likely due to mixtures of amino acids and peptides rather than to some trace or minor constituents of peptone functioning as germination stimulator. The requirement of large amounts of peptone as well as the pure amino acid phenylalanine further indicated the possible non-nutritive role of these substances in inducing germination of crowded conidia of Glomerella cingulata.

Glucose and C-D salts appeared to establish a state of equilibrium between germination and germination inhibition over a wide range of spore densities. Peptone, on the other hand, gave a bimodal response curve; the slope of the curve between 100 and 1000 conidia/mm. ${ }^{2}$ was different from those of lower as well as higher densities (Fig. 1). According to Dr J. G. Horsfall (private communication) permeation of alanine moiety might be necessary for germination. The phenyl group in phenylalanine would almost surely increase permeation of the alanine group and increase germination. The second approximation is- $(a)$ that alanine and phenylalanine are toxic in the concentrations used, and $(b)$ that they also prevent the action of the inhibitor (after they permeate). The deleterious and beneficial effects could generate the polymodal curve. Dosage response curve of the fungicide tetramethylthiuram disulphide (TMTD) on Macrosporium sarciniforme showed that toxicity of TMTD increased with increasing concentration of the fungicide but higher concentrations were less toxic and at much higher concentrations toxicity reappeared again (Dimond, Horsfall, Heuberger \& Stoddard, 1941). Horsfall \& Dimond (1963) considered that such bimodal response curves were generated by the action of two factors acting at different rates or in opposite directions. Petersen (1959) encountered such a non-linear bimodal response of infection of wheat plants to inoculum density of wheat rust uredospores. The observation of Petersen was especially interesting because of the role of a self-inhibitor in germination of uredospores. An unusual phenomenon was observed by Albert and co-workers (cf. Hewitt \& Nicholas, 1963) in connexion with the toxicity of oxine to Staphylococcus aureus; toxicity of oxine decreased with increase in concentration so much so that a saturated oxine was non-toxic. The 'concentration quenching' was due to oxine or to formation of non-toxic $3: 1$ oxine:iron complexes which result when oxine was in excess whereas unsaturated 1:1 and 2:1 oxine:iron complexes were toxic. Bimodal response was clearly evident in the alleviation of self-inhibition of germination of conidia of Glomerella cingulata by nutrients (Fig. 1, 3, 4, 5). The inhibition of germination of conidia might not be primarily due to nutritional deficiencies but to inhibitory substances in the conidia which may be functioning as antimetabolite(s). The self-inhibitory antimetabolite(s) may be excluded, complexed, or otherwise 
inactivated by large amounts of added nutrients. Failure of added trace elements to improve germination of crowded conidia further lent support to the view that the beneficial effect of repeated washing of conidia was due to leaching away of self-inhibitory substance(s) from the conidia and not to the exogenous supply of trace elements.

Financial support provided by U.S. National Science Foundation Grant GB-645 is gratefully acknowledged. We are indebted to Dr J. G. Horsfall and to Dr K. V. Thimann for valuable criticism and advice.

\section{REFERENCES}

Allen, P. J. (1957). Properties of a volatile fraction from uredospores of Puccinia graminis var. tritici affecting their germination and development. I. Biological activity. Plant Physiol. 32, 385.

Bell, A. A. (1960). Partial purification of self-inhibitors of germination from uredospores of Uromyces phaseoli var. typica. (Abstract). Phytopathology, 50, 629.

Cochrane, V. W. (1958). Physiology of Fungi. New York: John Wiley and Sons, Inc.

Drmond, A. E., Horsfall, J. G., Heuberger, J. W. \& Stoddard, E. M. (1941). Role of the dosage-response curve in the evaluation of fungicides. Conn. Agric. Expl. Station Bull. 451, 635.

Farkas, G. L. \& Ledingham, G. A. (1959). The relation of self-inhibition of germination to the oxidative metabolism of stem rust uredospores. Can. J. Microbiol. 5, 141 .

Forsyth, F. R. (1955). The nature of the inhibiting substance emitted by germinating uredospores of Puccinia graminis var. tritici. Can. J. Bot. 33, 363.

Goldsworthy, M. C. \& Green, E. L. (1938). Effect of low concentrations of copper on germination and growth of conidia of Sclerotinia fructicola and Glomerella cingulata. J. agric. Res. 56, 489.

Hawkins, L. A. (1913). The influence of calcium, magnesium and potassium nitrates upon the toxicity of certain heavy metals toward fungus spores. Physiol. Res. 1, 57.

HewitT, E. J. \& Nicholas, D. J. D. (1963). Cations and anions: Inhibitions and interactions in metabolism and in enzyme activity. In Metabolic Inhibitions, vol. 2. Ed. by R. M. Hochster \& J. H. Quastel. New York and London: Academic Press.

Horsfall, J. G. \& Dimond, A. E. (1963). A perspective on inoculum potential. $J$. Indian Bot. Soc. 38, 161.

Johnson, L. F., Curl, E. A., Bond, J. H. \& Fribourg, H. A. (1960). Methods for Studying Soil Microflora-Plant Disease Relationships. Minneapolis, Minn: Burgess Publishing Company.

LiN, C. K. (1945). Nutrient requirements in the germination of the conidia of Glomerella cingulata. Am. J. Botany, 32, 296.

Lingappa, B. T. \& Lingappa, Y. (1964). Self-inhibitory products of fungi. Bact. Proc. p. 35.

LINGaPPa, B. T. \& Sussman, A. S. (1959). Endogenous substrates of dormant, activated, and germinating ascospores of Neurospora tetrasperma. Plant Physiol. 34, 466.

Petersen, L. J. (1959). Relations between inoculum density and infection of wheat by uredospores of puccinia graminis var. tritici. Phytopathology, 49, 607.

Richardson, L. T. \& ThовN, G. D. (1962). Stimulation of spore germination and growth of Glomerella cingulata by copper and other heavy metal ions. Phytopathology, 52, 865 .

Thrmann, K. V. \& Edmondson, Y. H. (1949). The biogenesis of the anthocyanins. I. General nutritional conditions leading to anthocyanin formation. Arch. Biochem. 22, 33.

van Sumere, C. F., van Sumere-de Preter, C., Vining, L. C. \& Ledingham, G. A. (1957). Coumarins and phenolic acids in the uredospores of wheat stem rust. Can. J. Microbiol. 3, 847.

Waksman, S. A. (1932). Principles of Soil Microbiology. 2nd ed. Baltimore, Md.: The Williams and Wilkins Company.

Wruson, E. M. (1958). Aspartic and glutamic acid as self-inhibitors of uredospore germination. Phytopathology, 48, 595. 